desde la academia

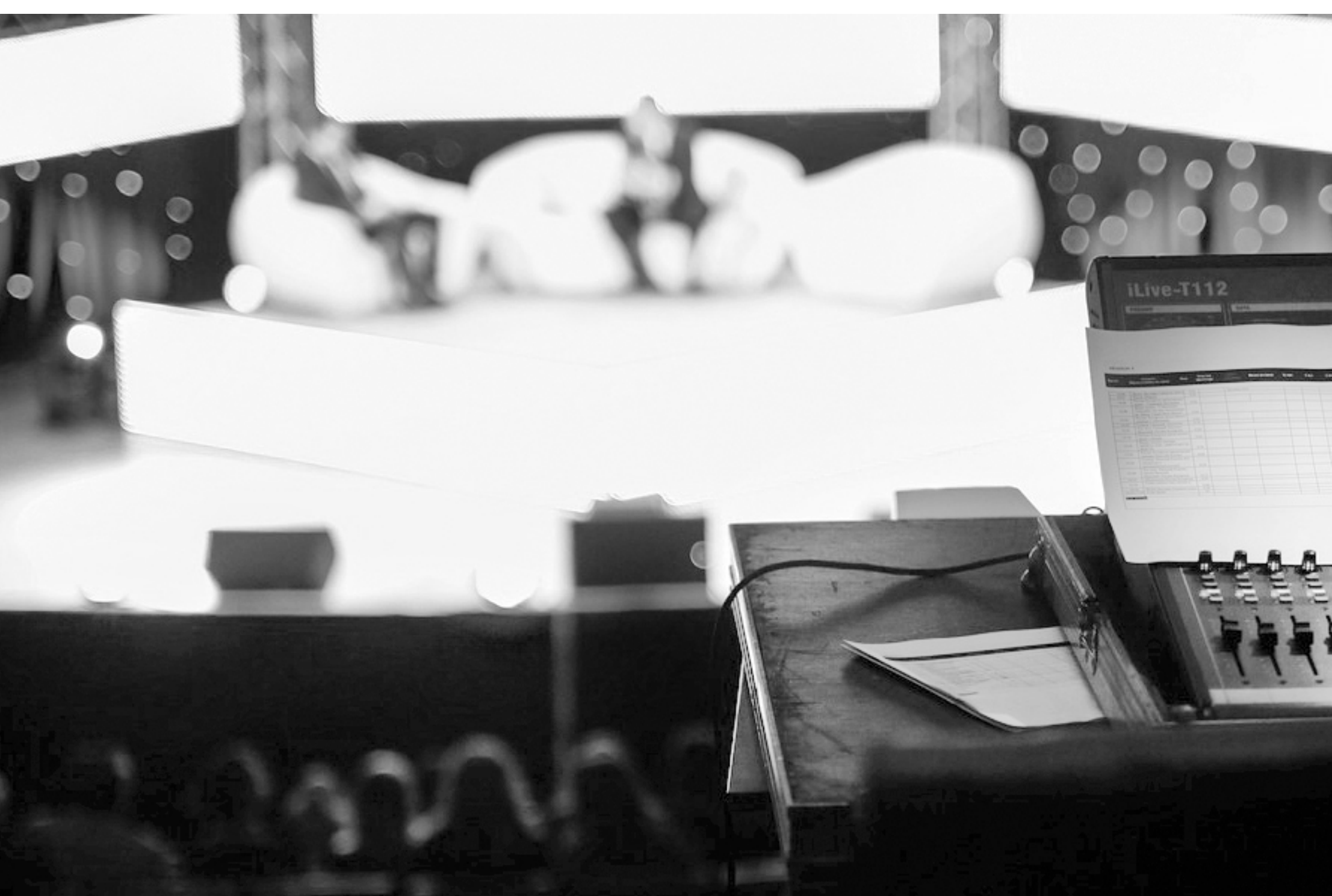




\section{Panelismo y noticia policial. Un análisis sobre la cobertura televisiva del asesinato de Fernando Pastorizzo}

\author{
Talk show and police news. An analysis \\ on television coverage of the murder \\ of Fernando Pastorizzo
}

DOI: https://doi.org/10.22235/d.v0i30.1722

Yamila Heram y María Paula Gago

\section{RESUMEN}

Este artículo se propone analizar el tratamiento de las noticias policiales en los programas de la televisión de aire argentina en los que predomina el panelismo. Para ello, se seleccionó una noticia puntual que puede catalogarse como un caso conmocionante: el asesinato de Fernando Pastorizzo por parte de Nahir Galarza, una joven con la que mantenía una relación. Para analizar la cobertura televisiva de este caso se articularon conceptos provenientes de perspectivas no coincidentes: el análisis crítico del discurso, la teoría de la noticia y la teoría del encuadre o framing. Entre los principales hallazgos se destaca la uniformidad de perspectivas que mostraron los panelistas en los programas analizados y las tensiones visibles al pensar el caso desde una perspectiva de género.

Palabras clave: noticia policial; panelismo; televisión; encuadre; violencia de género.

\section{ABSTRACT}

This article aims to analyze the treatment of police news in the programs of the Argentine air television in which the format of talk show prevails. To do so, we selected a specific piece of news that can be classified as a shocking case: the murder of Fernando Pastorizzo by Nahir Galarza, a young woman with whom he had a relationship. To analyze the television coverage of this case, concepts from different perspectives were articulated: the critical analysis of the discourse, the theory of news and the theory of framing. The main findings include the uniformity of perspectives shown by the panelists in the programs and the tensions that were observed when the case was considered from a gender perspective.

Keywords: police news; talk show; television; framing; gender violence.
Yamila Heram CONICET, Instituto de Investigaciones Gino Germani, Universidad de Buenos Aires, Argentina. http://orcid.org/00000002-9209-4571 yaheram@yahoo.com.ar

María Paula Gago CONICET, Instituto de Investigaciones Gino Germani, Universidad de Buenos Aires, Argentina. http://orcid.org/00000001-8148-1499 maria_paula_gago@ hotmail.com

Recepción: 15/11/2018 Aceptación: 30/03/2019 
$1::$ En la última década se han aprobado las siguientes leyes: Ley de Prevención y Sanción de la Trata de Personas y Asistencia a sus Victimas (26.364/08),

Ley de Educación Sexual Integral (26.150/06), Ley de Protección integral para prevenir, sancionar y erradicar la violencia contra las mujeres (26.485/09), Ley de Matrimonio igualitario $(26.618 / 10)$ y de Identidad de género (26.743/12).

2:: "Ni una menos" es un colectivo feminista que surgió en respuesta a la violencia machista. Para mayor información: www.niunamenos.org.ar

3:: Como consecuencia de la militancia de diversos colectivos feministas, la ley 26.791/12 introdujo en el artículo 80 del Código Penal argentino la aplicación de reclusión perpetua para quienes asesinen a familiares 0 personas con las que mantenian relaciones de pareja, así como para los crímenes contra mujeres cuando el perpetrador es hombre y media la violencia de género (Ley 11.179, 1984).

\section{Introducción}

La televisión continúa ocupando un lugar central en la vida cotidiana de los argentinos: según la Encuesta Nacional de Consumos Culturales 2017, realizada por el Sistema de Información Cultural de la Argentina, el $95 \%$ de la población mira televisión, que además es el medio audiovisual más elegido. La televisión de aire en este país se caracteriza por ofrecer una programación generalista basada en la competencia entre los canales. Una de las tendencias predominantes en la televisión abierta son los programas basados en la estructura de un conductor y un conjunto de panelistas que conversan y discuten sobre temas de actualidad, muchas veces a partir de informes televisivos.

Este trabajo se estructura a partir del cruce entre el tratamiento de la noticia policial y la televisión, con un interés particular por el formato que denominamos panelismo. Se parte de la noción de que los medios de comunicación, en las sociedades de masas, consolidan y difunden los imaginarios sociales (Baczko, 1999). Son una fuente de definiciones e imágenes de la realidad social que proporcionan un patrón de lo que es "normal”, empírica y subjetivamente (McQuail, 1999). Por su parte, la noticia policial cumple con un rol político y pedagógico: es un espacio desde el cual se reclama control social (Garland, 2005) a la vez que se tematiza sobre el bien y sobre el mal.

El propósito de este artículo, entonces, es observar el tratamiento de la noticia policial -a partir del análisis de un caso puntual- en los programas de panelismo de mayor audiencia que se emiten en la franja horaria de la tarde en la televisión de aire argentina. El objetivo es doble: por un lado, indagar la manera en que fue representado el caso y, por otro, entender dicho tratamiento en relación con las características del panelismo conversacional en programas que, por su frecuencia diaria y la cantidad de horas que duran, se ocupan de una variedad de temas diversos, con tensiones y matices.
El caso de estudio seleccionado es un asesinato ocurrido el 29 de diciembre de 2017 en Gualeguaychú, Entre Ríos. La víctima del hecho fue Fernando Pastorizzo, un joven de 20 años, y la victimaria fue Nahir Galarza, una joven de 19 años que mantenía una relación sentimental con él. La joven utilizó el arma reglamentaria de su padre policía para disparar dos veces contra la víctima, y fue condenada a prisión perpetua el 3 de julio de 2018, tras un juicio de gran exposición mediática que se difundió públicamente como el "caso Nahir Galarza”. Por el fuerte impacto que generó en la agenda de medios y en la opinión pública, este crimen puede considerarse un caso conmocionante, según la definición de Fernández Pedemonte (2010).

Un estudio de este tipo no puede comprenderse por fuera del contexto histórico en materia de género y ampliación de derechos ${ }^{1}$ en Argentina. En los últimos años han ganado visibilidad las demandas de las mujeres, en especial a partir de la primera marcha del "Ni una menos", realizada el 3 de junio de $2015^{2}$ y, más recientemente, con el debate en torno a la legalización del aborto y las denuncias del colectivo Actrices Argentinas sobre abusos y maltrato por parte de algunos actores. Los medios de comunicación, no sin tensiones, no pudieron ignorar estos reclamos sociales que visibilizaron el problema de la violencia de género. En el año en que se produjo el crimen que se analiza aquí, el Instituto de Políticas de Género Wanda Taddei informaba que cada 18 horas se producía un asesinato por violencia de género ("Se mata a una mujer", 2017). Por otra parte, en los medios se comenzó a utilizar con más frecuencia el concepto de femicidio para dar cuenta de esta problemática. ${ }^{3}$

Este contexto es importante para el caso de estudio porque la estrategia de la defensa de Nahir Galarza focalizó en que la joven era víctima de violencia de género, con la intención de atenuar la condena. Esto suscitó, en los programas televisivos, debates en torno a esta problemática. Por todo esto, el presente trabajo se orienta con 
siguiente hipótesis: la cobertura televisiva del asesinato de Fernando Pastorizzo estuvo en tensión entre querer brindar una mirada políticamente correcta sobre la cuestión de género y un visible desconocimiento de esta problemática, lo que promovió la desinformación y la estigmatización, tanto de Galarza en particular como de las mujeres en general.

\section{Aspectos metodológicos}

Para este trabajo se tomó una pequeña unidad de análisis conformada por los dos programas televisivos más vistos en el horario de tarde y en los que predomina el panelismo: Cortá por Lozano y El diario de Mariana (DDM), que se emiten por Telefé y Canal 13, respectivamente. La elección de los programas se basó en que se encuentran en competencia directa en los principales canales de televisión abierta y llegan a un público que ronda entre los 300.000 y 700.000 espectadores a diario, según IBOPE, una de las principales empresas dedicadas a la medición de audiencias en Argentina.

Al estar más de una hora y media al aire los días hábiles de la semana, una de las características de estos programas es la de poner en pantalla opiniones sobre los temas de la agenda pública y mediática. Los programas seleccionados, además, se caracterizan por tener conductoras mujeres que ofician de administradoras del tiempo y articuladoras de la conversación y las opiniones de un panel compuesto por periodistas, expertos y diversos personajes mediáticos. Estos programas suelen tener invitados especiales según los temas a tratar, que suelen tener como disparador la emisión de informes realizados con base en archivos televisivos, radiales y gráficos.

El recorte temporal para el análisis abarca desde el 5 de junio de 2018 al 4 de julio de 2018. Al tomar el mes previo a la sentencia pudimos advertir el encuadre que cada programa otorgó al caso. De todos modos, el principal foco de atención lo constituyeron las emisiones del día previo a la sentencia, del día de la sentencia y del día posterior, momento en el que los panelistas del $D D M$ y Cortá por Lozano interpretaron el veredicto judicial.

\section{Descripción de los programas analizados}

El Diario de Mariana (DDM) es un magazine de frecuencia diaria que se emite de lunes a viernes de 14:30 a 16:15 por Canal 13. El programa fue creado por la productora Mandarina Televisión, de Mariano Chihade, y trata temas de actualidad, con especial énfasis en política, policiales, espectáculos y humor. La conducción está a cargo de Mariana Fabbiani y la acompaña Diego Leuco, quien suele reemplazarla en sus ausencias. Como coconductor, Leuco tiene un lugar físico en el estudio que lo destaca del resto del panel. De este último forman parte los periodistas Luis Bremer, Martín Ciccioli, Carmela Bárbaro, Lucas Bertero, Sebastián "Pampito" Perello Aciar, Karina Iavícoli, Catalina D’Elia y Pablo De León. El programa está en el aire desde el 22 de mayo de 2013 de manera ininterrumpida. Es uno de los líderes de audiencia en esa franja horaria, con un rating promedio que ronda entre los $6 / 7$ puntos, según cifras de IBOPE. Durante la cobertura del asesinato de Pastorizzo, uno de los panelistas (Martín Candalaft) fue enviado a Gualeguaychú, desde donde ofició de notero.

Cortá por Lozano es un programa sobre actualidad y espectáculo producido por Kuarzo Entertainment Argentina y emitido por Telefé de lunes a viernes. La conductora es Verónica Lozano, ${ }^{4}$ que está acompañada por un panel mayoritariamente femenino: la modelo Nicole Neumann, la periodista Paola Juárez, la presentadora Connie Ansaldi y el periodista de policiales Mauro Szeta. La primera temporada se desarrolló entre el 27 de enero y el 29 de diciembre de 2017, con distintos horarios de emisión: 17:30 a 19:00, $18: 30$ a 20:00 y 19:00 a 20:00. El inicio de la segunda temporada fue el 19 de marzo de 2018 , en el horario de 14:30 a 16:00. Disputa el liderazgo de audiencia con El diario de Mariana y Los Especialistas del Show, ambos de Canal 13. Suele medir entre 6 y 7 puntos, según IBOPE.
4:: Cabe destacar que la conductora es psicóloga pero que, si bien en los programas se suele mencionar su profesión, en el caso analizado no se aprecia un enfoque de la noticia en el que prevalezca su mirada profesional. 


\section{Marco teórico}

Para categorizar los programas analizados nos basamos en la propuesta de los macrogéneros televisivos de Orza (2002), que permite distinguir los tipos de discursos en relación con los campos de referencia en que se organizan: externos (discurso referencial), internos (discurso ficcional) o mixtos (discurso de hibridación). Los primeros implican la representación de sus contenidos en relación con el campo de referencia externo: debate politico, noticieros, de actualidad, entre otros. Entre los segundos se ubican los que representan un campo de referencia imaginario o fantástico, aunque tengan aproximación con la realidad externa: telenovelas, series, dibujos animados y películas. Los discursos de hibridación son aquellos que representan sus contenidos combinando las formas de aproximación a lo ficcional y a lo referencial: programas infantiles, reality show, magazine, programas de espectáculos y entretenimiento.

Para este análisis los programas Cortá por Lozano y El diario de Mariana representan discursos de hibridación, como menciona Justo von Lurzer (2017):

Un formato híbrido entre el viejo magazine televisivo, el programa de chimentos y el informativo que funciona en general como un espacio de conversación sobre la propia televisión y retoma de cada uno de estos géneros sus aspectos centrales. Pueden incluir segmentos de cocina, espacios de información de actualidad -repaso de la información del día-, temas de interés general y amplias secciones de chimentos con panelistas y entrevistas en piso (p. 28).

De todos modos, vale aclarar que más allá de lo heterogéneo de los diferentes segmentos que suelen predominar en los programas aquí analizados, en lo que respecta específicamente al tratamiento del caso de estudio se presenta una mayor cercanía al discurso referencial.
La elección del caso de estudio se basó en su carácter conmocionante, de acuerdo con la definición de Fernández Pedemonte (2010):

Se considera conmocionante a un caso ya sea por la envergadura de los acontecimientos que narran o por la permanencia en la agenda pública y el grado de debate que desencadenan, fruto esto último de la decisión de los periodistas, hasta cierto punto aleatoria, al menos si se comparan tales casos conmocionantes con acontecimientos similares que pasan prácticamente inadvertidos (p. 21).

Para el análisis crítico de los programas articulamos conceptos provenientes de perspectivas no coincidentes, pero que permiten abordar el corpus desde diversos aspectos: el análisis crítico del discurso, la teoría de la noticia y la teoría del encuadre (framing).

Entendemos a la noticia como una forma del discurso público (Van Dijk, 1990) que se produce dentro de un marco socioeconómico y cultural más amplio, lo cual permite caracterizarla como una forma particular de práctica social, institucional. En este sentido, se abordan los textos a partir de una serie de preguntas propuestas por Van Dijk (1997): ¿Quiénes son los actores (protagonistas y secundarios) de las noticias? ¿Quiénes son los actores activos (agentes) y quiénes los participantes pasivos (pacientes)? ¿Qué acciones se subrayan, se describen o se ignoran? ¿Qué fuentes se citan y cómo se legitiman? ¿A quién se cita (o no) y con qué formulación estilística? Si bien Van Dijk recurre a estas preguntas para el análisis de la prensa, resultan pertinentes para analizar estos programas de televisión.

Para el estudio de la construcción de los discursos periodísticos tuvimos en cuenta conceptos fundamentales de la teoría de la noticia: jerarquización y estructuración de agendas (temática y atributiva); la noción de noticiabili- 
dad que sostiene cada órgano mediático; las modalidades discursivas o de enunciación específicas y la relación con las fuentes. Según Martini (2000), la teoría de la noticia puede definirse como aquella que intenta dar cuenta de las diferentes formas y procesos de construcción de la información periodística, lo que involucra a periodistas, fuentes de información y públicos.

De la teoría del framing tomamos el propio concepto de encuadre, que define a aquellos principios organizativos, compartidos socialmente, que trabajan simbólicamente para estructurar el mundo social de modo significativo (Reese citado en Aruguete y Koziner, 2014, p. 136). Retomando a Entman (citado en Koziner y Aruguete, 2016), señalamos que los rastros que los encuadres dejan en los textos pueden identificarse a partir de la presencia o ausencia de "ciertas palabras clave, una serie de frases, imágenes estereotipadas, fuentes de información y oraciones que proveen grupos de hechos o juicios reforzados temáticamente" (p. 11). ${ }^{5}$

\section{Características de la televisión abierta y del panelismo}

Existe una amplia literatura que problematiza y discute sobre la situación contemporánea de la televisión, en torno a si "está muriendo" o "entrando en una nueva fase” (Carlón, 2016, p. 77). Sin embargo, hay un punto en el que diversos autores (Verón, 2009; Carlón y Scolari, 2009; Piscitelli, 2009; Valdettaro, 2010) coinciden: se aprecia un desplazamiento hacia otras formas de consumo a partir de las múltiples pantallas y los servicios de streaming on demand, que se manifiestan -en menor o mayor medida- en intereses transitorios de consumo y personalización de la recepción.

Algunos datos en Argentina ilustran estas modificaciones: en la última década se ha producido una migración de la audiencia hacia la televisión por cable, mientras que entre 2006 y 2015 ha disminuido de manera sostenida el consumo de la televisión de aire. En abril de 2016 el total de audiencia del cable superó a los canales de aire (LAMAC, s/d). ${ }^{6}$ La tendencia de consumo se orienta hacia la televisión on demand, con Netflix como líder en servicio de streaming en América Latina. En el año 2011, Netflix ingresó en Argentina y en abril de 2017 tenía 847.458 suscriptores en el país. En segundo puesto se ubicaba Cine.arPlay con 477.944 y luego Onvideo, de Telefónica, con 121.065 (Baladrón y Rivero, 2017).

Ahora bien, ante tal estado de situación, ¿cuál es la relevancia de focalizar el análisis en la televisión abierta? ¿Por qué detenernos en los programas que se caracterizan por el panelismo televisivo? Entendemos que la televisión abierta es el lugar privilegiado de producción de discursos para los grandes públicos, a diferencia de la segmentación y microsegmentación de las ofertas de la televisión por cable, la televisión on demand y los servicios de streaming. Como se mencionó, la televisión sigue siendo el medio audiovisual más elegido entre los argentinos (Sistema de Información Cultural de la Argentina, 2017).

La televisión abierta argentina se encuentra conformada por cuatro canales de gestión privada -Canal 13, Canal 9, Telefé y América- y uno de gestión estatal, Televisión Pública. Las cinco emisoras se caracterizan por ofrecer una programación generalista que se organiza a partir de la competencia (Di Guglielmo, 2010). El canal que más se diferencia en este sentido es Televisión Pública que, al ser de gestión estatal, ofrece otro tipo de contenidos esperables en los medios públicos (Becerra, 2015; Arroyo, Becerra, García Castillejo y Santamaría, 2012; Ortega, 2010; Rincón, 2005; Martín Barbero, 2005; Fuenzalida, 1998, 2002, entre otros). ${ }^{7}$

Dentro de la oferta de la televisión abierta actual, una tendencia predominante es el formato del panelismo que, como se vio, se ubica dentro del discurso de hibridación (Orza, 2002). En este sentido, entendemos que los programas en los que predomina el panelismo funcionan como refuerzo y construcción de una agenda informativa que
5:: La teoría del encuadre se opone a los enfoques objetivistas que entienden que el periodismo refleja con objetividad aquello que informa. La mirada del framing se nutre de la sociologia interpretativa, una corriente que hace foco en que los individuos se aproximan a la realidad teniendo en cuenta las aportaciones de los demás. Por ende, los significados de la realidad que difunden los medios repercuten en los significados de esa misma realidad para las audiencias (Sádaba, 2001, 2007).

6:: Para mayor información consultar: Latin American

Multichannel Advertising Council (http://www. lamac.org).

7:: Estos autores coinciden en que los medios públicos deberían brindar diversificación de voces, pluralidad informativa e independencia del gobierno; emitir contenidos culturales/ educativos; tener una preocupación por la realidad local/regional y promover lo experimental. En Televisión Pública esta diferencia aparece en horarios periféricos (primera mañana, madrugada) en los que el encendido es menor (Heram, 2018). 
8:: Psicólogo que visita asiduamente el DDM para hablar de la "psicología" de las famosas. Con anterioridad habia participado de un reality romántico conducido por Andrea Politti, que se transmitía también por Canal 13. En este programa interrogaba a los participantes infieles. atraviesa los distintos géneros televisivos. En mayo de 2018 se llegaron a contabilizar 154 panelistas en 31 programas. El canal América fue el primero en ofrecer una programación basada fuertemente en la estructura del panelismo; en 2018, Canal 9 cambió su programación, que se basaba en enlatados, por esta misma tendencia (Heram, Toldeo, Merchert y Bleiz, 2017).

En conclusión, entendemos que si bien el mercado de los medios de comunicación está atravesado por tendencias que afectan los modos de consumo y que ponen en "crisis" a la televisión como medio centralizado de comunicación (Verón, 2009), esto no afecta el hecho de que los programas analizados ocupan una gran cantidad de horas de pantalla, con importantes mediciones de audiencia, e instalan temas y perspectivas que nos interesa problematizar. A su vez, cuando sucede un caso conmocionante, como el que se analiza aquí, los medios se ocupan de este y, en el caso de la televisión, le dedican una gran cantidad de horas de pantalla.

\section{Resultados y discusión}

El asesinato de Fernando Pastorizzo ocupó un lugar central en la agenda de los programas El diario de Mariana y Cortá por Lozano, como lo demuestran los minutos y días dedicados a la cobertura del caso. En el siguiente análisis se hará referencia a varias emisiones de estos programas, aunque el mayor énfasis se pondrá en el 3 de julio de 2018 (día de la sentencia) y el 4 de julio (día posterior de la condena a prisión perpetua). A continuación, los resultados se organizan en cuatro ejes que articulan las miradas teóricas propuestas: los actores de la noticia; las fuentes de la información; los encuadres; el panelismo y la perspectiva de género.

\section{Los actores de la noticia}

En este apartado se describe la manera en que ambos programas representaron a los diferentes actores involucrados en el acontecimiento y en la construcción de la noticia. Siguiendo a Van Dijk (1997), se distinguen los protagonistas, los actores de reparto y aquellos que aparecen como agentes pasivos, con el objetivo de comprender, mediante el análisis crítico del discurso, qué imágenes se construyeron sobre los actores, qué acciones se describían y cuáles se omitían. Cabe aclarar que la metodología del citado autor, propuesta originalmente para analizar medios gráficos, se retoma aquí con el propósito de encontrar indicios del contexto comunicativo (expresiones textuales, manifestaciones o expresiones de las condiciones de producción).

En ambos programas los protagonistas son Fernando Pastorizzo (la víctima) y Nahir Galarza (la victimaria). Ambos son representados como jóvenes de clase media y se enfatiza que la joven es hija de un policía. Se evidencia un importante contraste en relación a cómo los programas representan a los actores principales. Con el recurso de la pantalla partida, es recurrente el uso de fotografías que muestran a Galarza en ropa interior, traje de baño o ropa "sensual" y, en contraposición, a Pastorizzo con uniforme escolar, recostado en el pasto con su perro o tomando una selfie frente al espejo de un baño.

En cuanto a los actores de reparto, aparecen diferencias en los programas. En el caso del DDM aparece, con un rol sobresaliente en comparación con el resto, el psicólogo Gabriel Cartañá, ${ }^{8}$ quien tuvo contacto directo con Galarza en dos oportunidades como perito de parte. En Cortá por Lozano ocupa ese rol predominante el remisero que encontró a Pastorizzo herido, minutos después de recibir los disparos. Su figura es interesante porque, como se verá en los siguientes apartados, adquiere en el programa el papel de "héroe que frustró los planes de Nahir".

También dentro de los actores de reparto, en el DDM se identifican dos subgrupos. Por un lado, invitados a los que se convoca por su profesión: el abogado penalista Christian Poletti; la psiquiatra Blanca Huggelmann; el abogado de Galarza, José Ostolaza; el periodista de policiales de La Nación, Gustavo Carabajal y el exmánager 


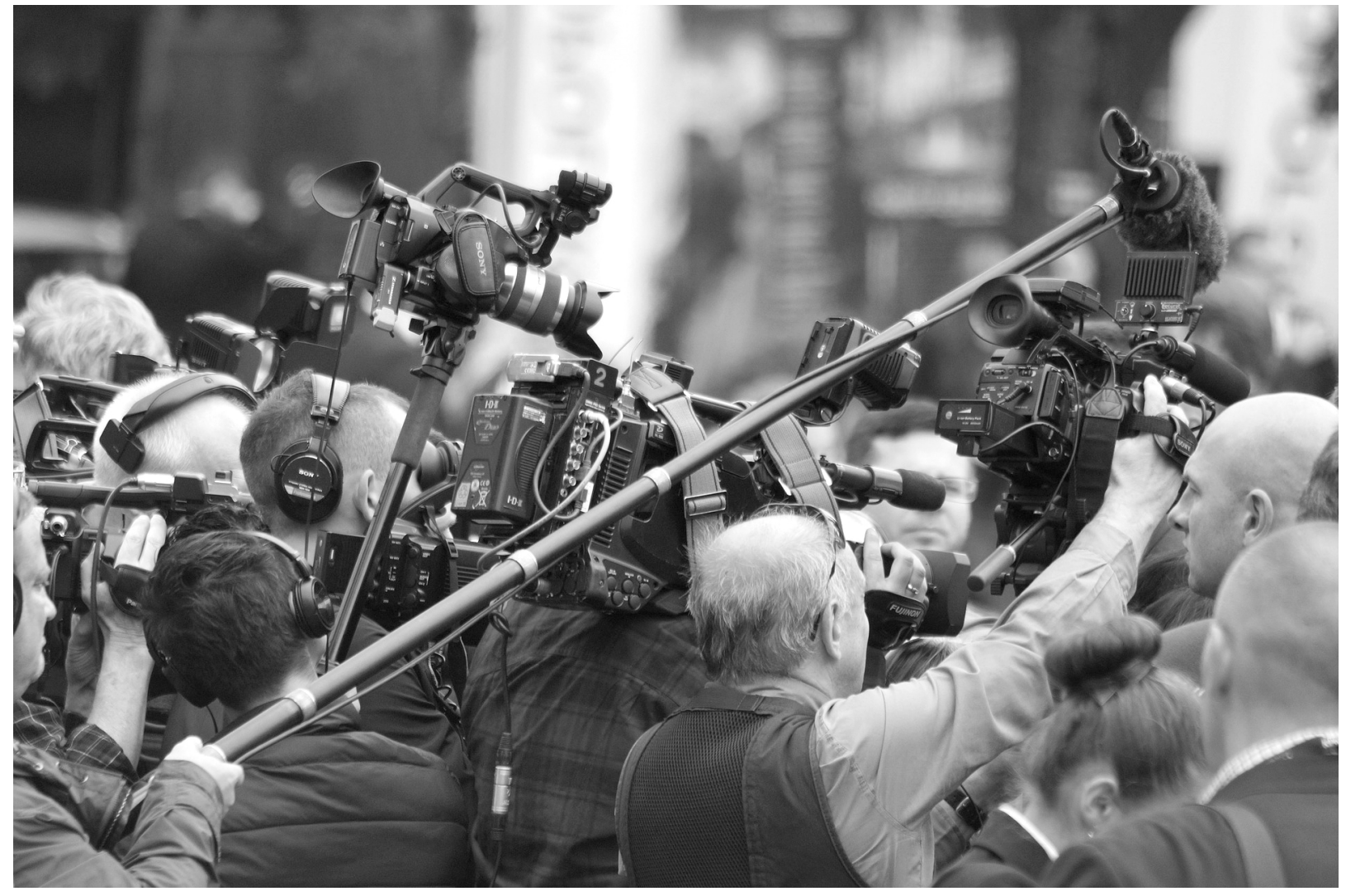

Foto: Cecilia Vidal

y vocero de Galarza, Jorge Zonzini. ${ }^{9}$ Por otro lado, aquellos que formaban parte del vínculo cercano de Pastorizzo: su padre, Gustavo Pastorizzo, y su amigo Elio, que adquiere centralidad el día de la sentencia.

En Cortá por Lozano aparecen Gustavo Pastorizzo, que adquiere centralidad debido a sus declaraciones luego de conocerse la sentencia, la psiquiatra Blanca Huggelmann y el perito Luis Olavarría, quien concurre como invitado para ofrecer información sobre la trayectoria de las balas. Por comunicación telefónica se le da voz al juez Mario Juliano, quien representa la única postura disidente: que la condena a Galarza fue excesiva.

Por último, se consideran actores secundarios y pasivos a quienes se mantienen al margen de las cámaras, no realizan declaraciones ni desarrollan acciones que produzcan puntos de giro en las narrativas mediáticas. En esta categoría aparecen la madre y hermana de Pastorizzo, y la madre, el padre, la abuela y el hermano de Galarza.

Esta categorización de los actores de la noticia nos permite comprender de qué modo se construyó el caso en cada programa: mientras que el $D D M$ puso mayor énfasis en los aspectos psiquiátricos de Galarza, Cortá por Lozano se centró en el testigo ocular de la agonía de Pastorizzo.

\section{Las fuentes de información}

Las fuentes periodísticas pueden definirse como aquellas "personas, instituciones y organismos de toda indole que facilitan la información que necesitan los medios para suministrar noticias" (De Fontcuberta citado en Ruiz y Albertini, 2008, p. 14). Estas cumplen un rol central puesto que "a menos que se trate de hechos programados... la mayoría de los periodistas no ha sido testigo de aquello sobre lo que informa" (Ruiz y Albertini, 2008, p. 14). ${ }^{10}$

Si bien la importancia de las fuentes radica en que junto con periodistas e información conforman la "triangulación básica operativa" (Martini, 2000) que posibilita todos los procesos de construcción de la noticia, su selección adquiere especial interés porque no es solo una decisión periodística, sino también política. Se trata de una operación que construye sentido, "que expresa una cierta lectura de los hechos, la línea editorial del medio y su compromiso con determinados sectores sociales" (Asociación Mundial de Radios Comunitarias América Latina y Caribe, 2008, p. 22).
9:: Zonzini fue contratado por la familia de Galarza para ser su representante frente a los medios. Cabe aclarar que es reconocido por ser mánager de modelos y actrices.

10:: Trasciende a los objetivos de este artículo realizar un recorrido por los principales aportes teóricos sobre las fuentes de información periodísticas. Al respecto véase Ruiz y Albertini (2008). 
Para clasificar a las fuentes de información elegimos la tipología que proponen Camps y Pazos (citado en Ruiz y Albertini, 2008, p. 18) y que se basa en la naturaleza de estas:

1. La observación directa.

2. La gente: protagonistas (víctimas, culpables, sospechosos, familiares, autoridades, allegados); voceros y jefes de prensa; contactos del periodista; agencias de prensa; otros periodistas.

3. Los documentos: cables, documentos de procedencia comprobada, documentos no convencionales (materiales escritos que cumplen el rol de fuentes), archivos periodísticos, redes informáticas, estadísticas, videos, etc.

4. Los otros medios: diarios y revistas, radio, televisión, agencias de noticias e Internet.

5. La parainformación: información que llega sin que el periodista salga a buscarla (visitas y llamados, comunicaciones anónimas, rumores, afiches callejeros, etc.).

A partir de esta clasificación, se aprecia que el $D D M$ y Cortá por Lozano comparten fuentes de la misma indole. Las fuentes más utilizadas fueron la observación directa; la gente, específicamente los protagonistas, los voceros y representantes, autoridades y los contactos de los periodistas; los documentos. En menor medida se incluyó a otros medios, como por ejemplo la presencia de Gustavo Carabajal o la lectura de crónicas redactadas por periodistas del diario Clarín y el uso de videos, provistos por terceros, en los cuales se la podía ver a Nahir declarar ante el juez o las cámaras de seguridad que la mostraban llegando a su casa aquel 29 de diciembre.
En el $D D M$, dentro de la categoría la gente, aparecen como protagonistas el padre de Fernando Pastorizzo $\mathrm{y}$, en el día de la sentencia, Elio, el mejor amigo de la víctima. La inclusión de ambos como fuente se debe a la cercanía y al parentesco que mantenían con el joven. En la subcategoría contactos del periodista aparece el psicólogo Gabriel Cartañá, quien se convirtió en una fuente privilegiada de consulta: era una voz autorizada para hablar de Galarza por haber estado en contacto directo con ella, pero su legitimación no solo provenía de "haberla visto", sino también de su profesión.

En la subcategoría voceros y representantes ubicamos al exmánager de Galarza, Jorge Zonzini, quien es invitado al programa del 29 de junio de 2018, última emisión antes de conocerse la sentencia. Sus declaraciones fueron utilizadas por la conductora, el coconductor y los panelistas como un boomerang (Marafioti, 1998), es decir, a partir de sus propios dichos lo desacreditan y desestiman su parecer sobre Galarza. Por ejemplo, en un intercambio con la panelista Catalina D'Elía, ella le cuestiona cómo puede sostener que los dos disparos que recibió Pastorizzo son accidentales, cuando en la escena del crimen los peritos solo encontraron una vaina en lugar de dos, de lo cual se deduce que una fue escondida. Zonzini argumenta que no es perito, que en todo caso es el enlace, la voz de la que está sin voz. De modo inmediato, la conductora lo interrumpe y sentencia: "igual el que está sin voz es Fernando Pastorizzo, no Nahir” (DDM, 29 de junio de 2018). Este intercambio ejemplifica el modo en que la conductora y los panelistas respondían a las declaraciones del entrevistado.

En Cortá por Lozano, a diferencia del DDM, es utilizado de manera privilegiada el tipo de fuente observación directa, ya que se entrevista al remisero que fue testigo ocular de la agonía de Pastorizzo. La inclusión de su testimonio se debe a que otorga veracidad a la historia, "puesto que nada puede reemplazar a los dichos reales de los testigos directos -sobre todo si 
son reproducidos en su versión exacta, coloquial" (Ruiz y Albertini, 2008, p. 19). Por otra parte, dentro de la categoría la gente, y de la subcategoría los protagonistas, el día de la sentencia se realiza una comunicación telefónica con el padre de Pastorizzo.

En lo referente a la subcategoría autoridades, en ambos programas se utilizaron fuentes oficiales vinculadas de modo directo con el proceso judicial, como el perito oficial y el perito de parte. Al contrario de lo que suele suceder en la cobertura de casos conmocionantes, en esta cobertura la policía no fue una fuente sobrerrepresentada (Caimari, 2007), sino que, por el contrario, casi ni se la mencionó. Probablemente esto se deba a que el padre de Galarza es policía.

En cuanto al tipo de fuente clasificada como documentos, en ambos programas se reprodujeron videos que muestran a Galarza declarando ante el juez y capturas de chats de WhatsApp entre ella y Pastorizzo. En el caso de Cortá por Lozano, el panelista Mauro Szeta muestra una impresión de pantalla con los mensajes y los presenta como la "sentencia de muerte de ella hacia él". En el DDM esas capturas son usadas para presentar a Galarza como una psicópata. En ambos programas, este documento aparece como fuente bajo la modalidad de atribución de reserva obligada, es decir, que la identidad de quien provee esos materiales no se menciona, porque no se puede develar (Borrat, 1989). ${ }^{11}$

Por otro lado, el movilero del $D D M$ y Mauro Szeta en Cortá por Lozano adquieren, en algunos momentos, el rol de observación directa. En el caso del movilero, porque al estar en el lugar donde transcurre el juicio tiene acceso a información variada y actualizada, lo cual habilita a que desde el estudio se lo consulte para corroborar o desechar trascendidos. En el caso de Szeta porque, al ser un periodista especializado en policiales, él mismo se posiciona (y los demás lo refuerzan) como la autoridad para brindar datos, ya sea porque tuvo acceso a la lectura de algún expediente o porque cuenta con la experiencia necesaria para adelantar, a sus compañeros y al público, lo que acontecerá.

Por último, es pertinente señalar que los rumores -que funcionan como fuentes no chequeadas y nutren a las coberturas cuando escasea la información oficial (Allport y Postman, 1947) - no ocuparon un lugar relevante en los programas que se emitieron inmediatamente antes y después de la sentencia. Esto puede deberse a que los principales trascendidos ya habían sido corroborados o desechados por la Justicia. Como la familia Galarza se mantuvo apartada de las coberturas mediáticas, solo circularon trascendidos sobre declaraciones que el padre de Galarza realizó a algún panelista en la modalidad de off the record.

Tras analizar la utilización de las fuentes detalladas, se puede concluir que ambos programas mantuvieron una mirada incriminatoria hacia Galarza. Esto puede verse, por ejemplo, en la permanente consulta del $D D M$ al psicólogo Gabriel Cartaña, para conocer detalles de lo que el programa denomina la "mente criminal de Nahir", asi como en la centralidad que Cortá por Lozano le otorga al remisero, cuyo relato permite describir una escena del crimen "premeditada", tal como menciona Szeta: "es un callejón sin salida, es un lugar diagramado para alguien que quiere salir impune” (emisión de 3 de julio).

\section{El encuadre}

Como se mencionó, el encuadre es un principio organizativo que opera a nivel simbólico y estructura el mundo social de modo significativo (Reese, 2001 cit. por Aruguete \& Koziner, 2014, p. 142). Si bien estos establecen los límites dentro de los que se enmarca una cuestión, no trabajan a nivel de los contenidos seleccionados dentro de la información, sino que constituyen "una idea que provee un contexto dentro del cual los eventos son presentados" (Tankard citado en Aruguete \& Koziner, 2014, p. 142). En consecuencia,
$11::$ Según Borrat, hay tres modos posibles de atribución: directa (se cita información y se identifica la fuente); con reservas (se cita la información, pero no la fuente, sólo se la insinúa para orientar al público sobre la procedencia) y la de reserva obligada. 
“actúan ante la sensibilidad del público y... aceleran respaldo u oposición respecto de un determinado escenario" (Aruguete, 2013, p. 213). De allí la importancia de analizarlos.

En el $D D M$, el encuadre del caso ancla en marcos interpretativos que se nutren de la criminología positivista de principios del siglo XX, según la cual el individuo llega al delito por acción de alguna tara mental, no solo genética, sino psíquica (Elbert, 1998). De acuerdo con Caimari (2012), la criminología argentina -que influyó y alimentó con sus estereotipos y categorizaciones los enfoques de la prensa gráfica de principios de siglo XX sobre los hechos delictivos- cimentó un nuevo "sentido común criminológico" que habilitó a los relatos periodísticos policiales explicar las causas del crimen a partir de patologías individuales, psicológicas o sociales. Este encuadre se advierte por el tipo de invitados (psicólogos y psiquiatras) y por el tipo de preguntas y comentarios realizados por la conductora y el panel, así como por los zócalos sobreimpresos que remarcan "la mente criminal de Nahir". Algunos ejemplos de estos últimos son:

¿Cómo es la mente de la persona que mata? En vivo, el psicólogo que atendió a Nahir en la cárcel (emisión del 14 de junio de 2018).

No hay más secreto profesional. Gabriel Cartañá: "ahora puedo contar cómo es Nahir" (3 de julio de 2018).

¿No siente culpa? Nahir Galarza sonriente durante la audiencia. Le gritó mentirosa a la madre de su víctima (5 de junio de 2018).

En relación al tipo de preguntas que se realizaban -en especial al psicólogo y a la psiquiatra- resulta notorio el interés por conocer aspectos de la psiquis de Galarza:
¿Es consciente de haber matado a alguien y que se arruinó la vida? (3 de julio, pregunta al psicólogo Cartañá).

¿Lo admiraba a Pastorizzo? ¿Jugaba a hacerlo sufrir? (3 de julio, pregunta a Cartañá).

¿Por qué no es sana la relación con los padres? (3 de julio, pregunta a Cartañá).

¿Hay algún trauma en ella por el hecho de que el padre mató a cuatro personas como policía y lo exoneraron? (3 de julio, pregunta a la psiquiatra Huggelmann).

En Cortá por Lozano el encuadre presenta una predominancia de sensacionalismo en las modalidades enunciativas (Steimberg, 1987). Lo “psiquiátrico" es tema de interés, pero queda en segundo plano. Este tipo de encuadre se observa en la elección de los entrevistados, así como en los zócalos y preguntas. En cuanto a los entrevistados, como se dijo, se destina una gran cantidad de tiempo al remisero. Al ser testigo ocular de la agonía de la víctima, se le otorga una entidad que se organiza en un binomio dicotómico: "un crimen perfecto frustrado" por "un héroe" (el remisero) contra una "asesina desenmascarada”. Algunas de las preguntas que se le realizan al remisero, en la emisión del 3 de julio, ponen en evidencia lo afırmado:

¿Creés que frustraste sus planes?

¿Podrías haberlo salvado?

¿Cómo fueron los últimos minutos de Fernando?

¿Le contaste al padre cómo fueron los últimos minutos de Fernando?

¿Sabés que le cambiaste la vida a la familia de Fernando? 
También aparecen elementos melodramáticos en las preguntas que le realizaron al padre de Pastorizzo, a quien llamaron por teléfono en la emisión del 3 de julio:

¿Cómo te sentís con el fallo?

¿Cómo sigue hoy tu vida?

El encuadre amarillista y melodramático se refuerza en los zócalos:

Exclusivo: habla el remisero que intentó salvar a Fernando (3 de julio de 2018).

"La última agonía de Fernando la vi yo" (3 de julio de 2018).

El recorrido que hizo Nahir la noche del crimen (3 de julio de 2018).

¿Cómo mató Nahir a Fernando? (4 de julio de 2018).

Si bien en el $D D M$ se enfatiza en aspectos vinculados con la criminología positivista y en Cortá por Lozano en el enfoque sensacionalista y melodramático, ambos programas comparten el encuadre respecto al "fallo ejemplar e histórico". No se observan voces disidentes entre los integrantes de los programas, y aquellas opiniones que cuestionan lo excesivo de la condena aparecen en las voces de los invitados. En el caso del $D D M$ con el abogado penalista Christian Poletti y en Cortá por Lozano mediante la comunicación telefónica con el juez Mario Juliano. Ambos argumentan desde lo jurídico y citan al estatuto de Roma, que establece que los genocidas tienen 30 años de cárcel como pena máxima, por lo que resulta excesiva la condena de 35 años para Galarza.
Los zócalos en ambos programas refuerzan este encuadre:

Fallo histórico: Nahir Galarza condenada a prisión perpetua (Cortá por Lozano, 3 de julio de 2018).

Nahir es la mujer más joven condenada a cadena perpetua (Cortá por Lozano, 3 de julio de 2018).

Nahir Galarza, la mujer más joven de la historia criminal en recibir prisión perpetua (DDM, 3 de julio de 2018).

En relación con estos encuadres, es importante retomar lo dicho sobre el rol político y pedagógico que cumplen las noticias policiales (Garland, 2005). Tal como establecen Martini y Pereyra (2009):

Son interpretaciones ancladas en matrices culturales cuyos orígenes cruzan los planos de la tradición y de la modernidad, de la religión y la ley, los de la historia y las memorias sociales, cuyos recorridos se organizan durante la constitución del Estado liberal moderno y el aporte de la primera criminología (p. 11).

Desde los relatos sobre el delito se delimitan y marcan fronteras en el interior de una cultura. También se articulan delincuentes, víctimas, una noción de Estado, de política (Ludmer, 1999). En otras palabras: estas narrativas instauran representaciones sobre la propia identidad y las de los otros. No se trata de un segmento "inocente" destinado a alimentar el morbo de las audiencias, sino que, por el contrario, está cargado de sentido e intencionalidad.

Por otra parte, en ambos programas se observa una tensión derivada de la mención a aspectos vinculados
12:: Durante las coberturas se utilizaron placas con la leyenda: "Si sos víctima o conocés a alguien que sufra violencia de género, llamá al 144 las 24 horas". La resolución 1222/2013 de la Autoridad Federal de Servicios de Comunicación Audiovisual (AFSCA, 2013) recomienda a los titulares de licencias de servicios de comunicación audiovisual incluir esta leyenda cuando difunden noticias sobre violencia de género. 


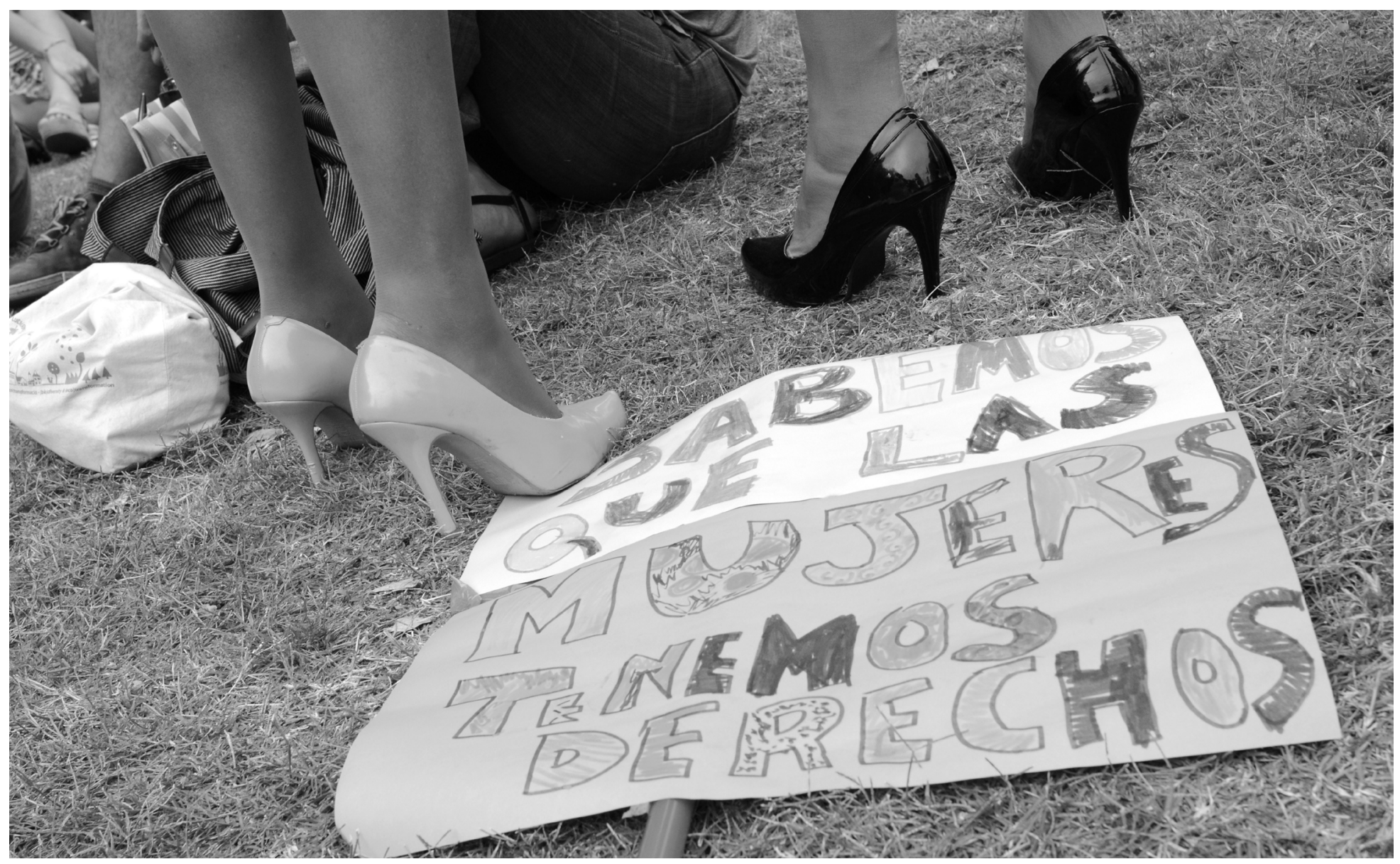

Foto: Cecilia Vidal

con la violencia de género y, al mismo tiempo, del intento por desmarcar al caso de esta perspectiva. ${ }^{12}$ Esto se puso en evidencia en la incomodidad de las conductoras y los panelistas, así como en muestras de desconocimiento sobre la problemática.

Por ejemplo, en ambos programas se alude a que la cobertura del caso lleva el nombre de la victimaria y no de la víctima, como ocurre usualmente, lo que deja entrever que debería enfatizarse sobre esta última. Asimismo, resulta llamativo que son algunos invitados, y no los panelistas o las conductoras, quienes advierten aspectos con perspectiva de género:

Los femicidios pasan uno cada 30 horas y no llaman tanto la atención (Blanca Huggelmann en Cortá por Lozano, 4 de julio de 2018).

Me gustaría que el tiempo justo que se le dedicó a este caso, donde hay una mujer que mató a un hombre, se aplique a hombres que matan mujeres (Gabriel Cartañá en El diario de Mariana, 3 de julio de 2018).
Sin embargo, y en contradicción con estas menciones, en los programas se focaliza en describir casos en los que las mujeres han cometido asesinatos (en especial en Cortá por Lozano), aun cuando las estadísticas indican que quienes asesinan diariamente a mujeres, por el hecho de ser mujeres, son hombres. Otro ejemplo que ilustra el desconocimiento o cierta confusión sobre lo que implica la violencia de género se observa en los comentarios del periodista Mauro Szeta (Cortá por Lozano):

¿Ustedes creen que este tribunal recontra observado por millones de argentinos si hubiese encontrado un atisbo mínimo de violencia de género no le hubiese atenuado la pena a Nahir? Digo, lo planteo porque muchos dicen que parece alta la pena, que no han tomado como atenuante nada (4 de julio de 2018).

De dicho razonamiento se infiere que un tribunal observado por la sociedad dictaminaría sentencias justas.

En conclusión, teniendo en cuenta los encuadres de cada programa se puede afirmar que, si bien el delito es una categoría flexible y sus modos de narración 
adquieren particularidades específicas en cada período histórico (Ludmer, 1999), las series informativas que instalan determinados modelos delincuenciales o los casos conmocionantes, como el analizado, habilitan modos de reclamo por parte de los medios de prensa.

En virtud de los marcos interpretativos en los que se anclaron las coberturas, se advierte la configuración de una narrativa presente en las crónicas policiales desde antaño (Gago, 2017) que tiende a demandar un castigo ejemplar y la aplicación de la pena máxima, pero que en este caso de estudio adquiere la particularidad de combinarse con una notoria banalización y desconocimiento de la perspectiva de género, sobre la que nos extendemos a continuación.

\section{Panelismo y perspectiva de género}

En este apartado final enfocamos en cómo el panelismo de los programas analizados favoreció la cosificación de la victimaria y su estigmatización. Esto se aprecia en la manera en que el foco de atención estuvo puesto en la figura de Galarza, en la elección de las fotografías con que se la representaba, en su "mente criminal”, en la relación con su familia, en las características de la cárcel a la que sería trasladada, los tratos diferenciados que recibía en la comisaría por ser hija de un policía, entre otras cuestiones. Vale la pena reiterar que en los medios de comunicación el caso fue difundido con el nombre de ella y no de la víctima, como es usual en estos hechos.

En los dos programas analizados las conductoras ofician de moderadoras: son quienes dan la palabra, presentan a los invitados, cambian de tema e insertan las publicidades. Si bien una de las características típicas de estos programas es la diversidad de los panelistas, que representan diferentes posiciones, en la cobertura de este caso no hubo diversidad de matices. Las únicas voces diferentes, que cuestionaron la condena a prisión perpetua para Galarza, aparecieron mediante comunicación telefónica o través de las declaraciones de apenas algunos de los invitados.

En Cortá por Lozano quienes ocupan roles más destacados son Mauro Szeta, periodista especializado en policiales y Connie Ansaldi, que representa las opiniones más pasionales en torno al tema, muestra una gran empatía con la familia de Pastorizzo y es quien llama al padre durante la emisión del 3 de julio, situación que deja en desconcierto al padre porque no sabía que estaba al aire. En El diario de Mariana, Diego Leuco y el movilero Martín Candalaft son quienes tiene más injerencia en torno al tratamiento que se le da al caso. En ambos programas se destaca un panelista masculino que es quien representa la mirada más crítica e incriminatoria a Galarza. En el caso del $D D M$ ese rol lo cumple Diego Leuco y en Cortá por Lozano, Mauro Szeta.

Encontramos ciertas similitudes en los programas en cuanto a la utilización de "recursos pedagógicos". En el caso del $D D M$, y con el objetivo de explicar o enfatizar en la personalidad de Galarza, se emplea una gran pantalla en la que se muestran los chats y el panelista-movilero remarca ciertas frases o palabras que son el disparador para "querer entender la mente de Nahir" (DDM, 12 de junio de 2018). En Cortá por Lozano se utiliza una hoja de tamaño A4 con gráficos que explican la trayectoria de la bala que asesinó a Pastorizzo, en consonancia con un tratamiento más sensacionalista por parte de ese programa.

También se observan similitudes en torno al desconocimiento por parte de los panelistas, conductoras y algunos invitados sobre qué es la violencia de género. En Cortá por Lozano se observa esta tensión en torno al hecho de tener que mencionar que todos los días se cometen femicidios y el dar espacio a un invitado -el perito Luis Olavarría- para hablar de mujeres asesinas, con especial foco en los casos Claudia Sobrero y Sandra Sabinelli. ${ }^{13}$
13:: La primera es la mujer que estuvo más tiempo en prisión por haber asesinado y a la segunda se la menciona por el asesinato de sus padres. 


\section{De esta manera}

se ancla en la condición femenina de quien habría cometido el delito (...) se plantean -de manera voluntaria o no- un conjunto de mandatos sociales que, además de anacrónicos, son formas de construcción y naturalización de las relaciones de desigualdad entre varones y mujeres (Defensoría del Público, 2016, p. 21).

En el $D D M$ también se observa una suerte de desconcierto sobre cómo abordar el tema. Por ejemplo, el invitado Gustavo Carabajal, periodista de policiales del diario La Nación, afirma que si Galarza hubiese sufrido violencia de género lo hubiera podido solucionar rápido porque, al ser hija de un policía, "hubiese tenido a quien acudir". Este comentario advierte una clara banalización de lo que implica sufrir violencia de género, y declaraciones de este tipo han aparecido lo largo del programa sin que la conductora o los panelistas hicieran ningún tipo de acotación o advertencia.

De acuerdo con una guía para periodistas elaborada por Unicef (2017, p. 8), las agendas que construyen los medios responden a una lógica hegemónica, que es patriarcal y "repite en sus estereotipos sentidos que perpetúan la asignación arbitraria de roles fijos, marcados por la división por género y también por edad". Por ejemplo, en relación con las imágenes que se muestran de Galarza, muchas son fotografías en bikini: Cortá por Lozano abunda más en este tipo de imágenes, mientras que el $D D M$ las intercala con las del juicio. El uso de estas fotografías entra en contradicción con lo que recomienda la Guía para el tratamiento periodístico responsable de noticias policiales, elaborada por la Defensoría del Público (2016), que advierte sobre prescindir de la construcción de "representaciones sexualizantes" (p. 23). rno a los programas de hibridación y los derechos sexuales y de género ver Justo von Lurzer (2017).
Por otra parte, un zócalo del programa $D D M$ del 14 de junio de 2018 ilustra otra carencia de perspectiva de género al momento de tratar la noticia: "Sexo, pasión y crimen: los chats de Nahir Galarza y Fernando Pastorizzo". El encuadre que plantea este mensaje remite a la clasificación del crimen como "pasional", una concepción que ha sido advertida como errónea por diferentes organismos y colectivos feministas.

De acuerdo con Cremona (citado en Unicef, 2017, p. 14) la perspectiva o visión de género es una categoría analítica que toma los estudios emanados desde las diferentes perspectivas "académicas de los feminismos para, desde esa plataforma teórica, cuestionar los estereotipos y elaborar nuevos contenidos que permitan incidir en el imaginario colectivo de una sociedad al servicio de la igualdad y la equidad". En relación a esta mirada, resultan claras las carencias de ambos programas a la hora de abordar la noticia desde una perspectiva de género. Quizá uno de los aspectos más llamativos del papel de los panelistas y las conductas en la cobertura de esta noticia fue la incomodidad que manifestaron en el tratamiento del tema en tensión con la cosificación del caso. ${ }^{14}$ En líneas generales se observó uniformidad de voces, tanto en los invitados como en los panelistas que, más allá de las diferencias estilísticas de cada uno, celebraron el "fallo ejemplar" de la sentencia.

\section{Conclusiones}

Del análisis del tratamiento que recibió el asesinato de Fernando Pastorizzo en los programas de panelismo de la televisión abierta argentina pueden extraerse algunas conclusiones relevantes para pensar la cobertura de noticias policiales en este tipo de formatos televisivos.

En relación a los actores, se vio que tanto Nahir Galarza y Fernando Pastorizzo fueron representados como pertenecientes a una clase media urbana, pero hubo un notorio contrapunto en las fotografías que se exhibieron de ambos: ella aparece con poca ropa y pose sensual mientras que a él se lo muestra con el uniforme 
escolar o con su perro. Los otros actores consultados por los programas son allegados a los protagonistas o testigos que permitieron reconstruir el día del asesinato y otorgar "pistas" sobre los rasgos de personalidad de ambos protagonistas y de la relación que mantenían.

En lo que respecta a las fuentes consultadas (psiquiatras, amigo de Pastorizzo, testigos oculares y forenses, entre otros), estas resultaron viables para incriminar a Galarza y reforzar el reclamo de la pena máxima para ella. Es decir, para justificar una sentencia que los dos programas analizados habían dictaminado antes de que la Justicia diera a conocer su veredicto.

En relación a los encuadres, que se advierten por el tipo de preguntas y comentarios realizados por las conductoras y el panel, los zócalos sobreimpresos y la selección de invitados, hubo matices en los programas analizados. En Cortá por Lozano predominó el sensacionalismo, el énfasis en el aspecto escabroso del caso, mientras que "lo psiquiátrico" quedó relegado. En el $D D M$, en cambio, se privilegió este aspecto, con referencias a la "mente criminal" de Galarza y las causas que la llevaron a matar a Pastorizzo. Más allá de estas diferencias, ambos programas consideraron que el fallo era "ejemplar e histórico".

Si bien una de las características distintivas del panelismo televisivo es lo heterogéneo de las posturas de los participantes, en este caso no se observaron voces disidentes en torno lo excesivo de la condena o el tratamiento desigual que se brindó a este caso en relación con uno del mismo tipo en el que el asesino es un hombre. La tensión en cuanto a la perspectiva de género fue evidente en ambos programas, en los que aparecían al mismo tiempo menciones a aspectos vinculados con la violencia de género y mensajes que se desmarcaban de esta mirada o mostraban desconocimiento sobre la problemática.

En ambos casos, las conductoras actuaron como moderadoras de la discusión, aunque también se apreciaron diferencias. Verónica Lozano, a pesar de que por ser psicóloga podría haberse valido de sus conocimientos para abordar el caso, se posicionó en su rol de conductora. Aunque se notaba que entendía ciertos tecnicismos, en todo momento cedió la palabra a los especialistas invitados para que explicaran, por ejemplo, qué era una personalidad psicópata. Mariana Fabbiani, por su parte, manejaba los debates, pero opinaba de modo contundente cuando no coincidía con alguna de las apreciaciones de los invitados o los panelistas.

El recorrido aquí presentado ofrece un panorama interesante que permite continuar indagando en torno al tratamiento de la noticia policial en la televisión de aire, ampliando la mirada con nuevas preguntas de investigación: ¿Qué tipo de cobertura realizan estos programas cuando el asesino es un hombre? ¿Qué tratamiento recibe este tipo de casos en otros géneros televisivos, como los noticieros? ¿Cómo se podría haber tratado el caso desde la perspectiva de género? ¿Qué convenciones del género televisivo se podrían repensar? Estas preguntas son solo algunos ejes de los que futuras investigaciones podrían ocuparse para identificar tensiones, matices y diferencias en el análisis de casos conmocionantes.

\section{Referencias}

Allport, G. W., y Postman, L. (1982). La psicología del rumor. Buenos Aires, Argentina: Editorial Psique.

Arroyo, L., Becerra, M. García Castillejo, A., Santamaría, 0. (2012). Cajas mágicas. El renacimiento de la televisión pública en América Latina. Madrid, España: Tecnos.

Aruguete, N. (2013). La narración del espectáculo político: pensar la relación entre sistema de medios y poder político. Austral Comunicación, 2 (2), 205-216. Recuperado de http://www.austral.edu.ar/ojs/index.php/australcomunicacion/article/view/7를 Aruguete, N., y Koziner, N. (2014). La cobertura mediática del "7D" en la prensa argentina. Aplicación de encuadres noticiosos genéricos a los principales diarios nacionales. Anuario Electrónico de Estudios en Comunicación Social, 7(1). Recuperado de https:// www.udesa.edu.ar/sites/default/files/paperaruguete.pdf 
Asociación Mundial de Radios Comunitarias América Latina y Caribe. (2008). El continente es el contenido. Manual de estilo de la agencia informativa Púlsar. Recuperado de http://documentos.amarcuruguay.org/ManualPulsar.pdf

Autoridad Federal de Servicios de Comunicación Audiovisual. (2013). Resolución 1222/13. Recuperado de https://www. enacom.gob.ar/multimedia/resoluciones-afsca-comfer/ pecfr/2013/R20131222.pdf

Baczko, B. (1999). Los imaginarios sociales. Memorias y esperanzas colectivas. Buenos Aires, Argentina: Nueva Visión.

Baladrón, M., y Rivero, E. (2017). La regulación de las plataformas 0TT audiovisuales: un modelo para armar. Revista Fibra. Tecnologías de la Comunicación, 16. Recuperado de http://papel.revistafibra.info/la-regulacion-las-plataformas-ott-audiovisuales-modelo-armar/

Becerra, M. (2015). De la concentración a la convergencia. Políticas de medios en Argentina y América Latina. Ciudad Autónoma de Buenos Aires: Paidós.

Borrat, H. (1989). El periódico, actor político. Barcelona, España: G. Gili.

Caimari, L. (2007). La ley de los profanos. Delito, justicia y cultura en Buenos Aires (1870-1940). Buenos Aires, Argentina: Fondo de Cultura Económica.

Caimari, L. (2012). Mientras la ciudad duerme. Pistoleros, policías y periodistas en Buenos Aires, 1920-1945. Buenos Aires, Argentina: Siglo XXI.

Carlón, M. (2016). Después del fin. Una perspectiva no antropocéntrica sobre la posttv, el post-cine y y youtube. Buenos Aires, Argentina: La Crujía.

Carlón, M., y Scolari, C. A. (Eds). (2009). El fin de los medios masivos. El comienzo de un debate. Buenos Aires, Argentina: La Crujía.

Defensoría del Público. (2016). Guía para el tratamiento periodístico responsable de noticias policiales. Recuperado de https://defensadelpublico.gob.ar/ wp-content/uploads/2016/10/Gu\%C3\%ADa-Policiales-PDF-WEB-2019.pdf

Di Guglielmo, H. (2010). La programación televisiva en guerra.
Buenos Aires, Argentina: La Crujia.

Elbert, C. A. (1998). Manual básico de criminología. Buenos Aires, Argentina: Eudeba.

Fernández Pedemonte, D. (2010). Conmoción pública: los casos mediáticos y sus públicos. Buenos Aires, Argentina: La Crujía.

Fuenzalida, V. (1998). Situación de la TV-Pública en América Latina. Diálogos de la Comunicación, 53. Recuperado de http://dialogosfelafacs.net/wp-content/uploads/2012/01/53-revista-dialogo-la-situacion-de-la-television.pdf

Fuenzalida, V. (2002). Televisión abierta y audiencia en América Latina. Buenos Aires, Argentina: Norma.

Gago, M. P. (2017). Modelos delincuenciales y narrativas mediáticas sobre el delito. Los diarios argentinos Clarín y Crónica durante el periodo 1976-1979. Austral Comunicación, 6(2), 305-342. Recuperado de http://www. austral.edu.ar/ojs/index.php/australcomunicacion/article/view/203/236

Garland, D. (2005). La cultura del control: crimen y orden social en la sociedad contemporánea. Barcelona, España: Gedisa.

Heram, Y. (2018). Televisión Pública: un estudio exploratorio de su programación. Estudos em Comunicação, 1(26), 65-80.

Heram, Y., Toledo, C., Merchert, M., y Bleiz, C. (2017). Tendencias actuales de los canales de aire de la televisión argentina. Ciencias Sociales, 94, 138-141.

Justo von Lurzer, C. (2017). Esto le puede servir a alguien. Demandas de derechos en el espectáculo televisivo contemporáneo en Argentina. Estudos em Comunicação, 25(1), 23-52.

Koziner, N., y Aruguete, N. (2016). El "7D" en los diarios económicos argentinos. Aplicación de encuadres noticiosos genéricos a la cobertura de la controversia judicial entre el Gobierno y el Grupo Clarín. Comunicación y Medios, 33, 7-34.

Ley 11.179. (1984). Código Penal de la Nación Argentina. 
Recuperado de http://servicios.infoleg.gob.ar/infoleglnternet/anexos/15000-19999/16546/texact.htm

Ludmer, J. (1999). El cuerpo del delito. Un manual. Buenos Aires, Argentina: Perfil.

Marafioti, R. (Comp.). (1998). Recorridos semiológicos. Signos, enunciación y argumentación. Buenos Aires, Argentina: Eudeba.

Martín-Barbero, J. (2005). Claves de debate: televisión pública, televisión cultural: entre la renovación y la invención. En 0. Rincón (Eds.), Televisión pública: del consumidor al ciudadano(pp. 35-68). Buenos Aires, Argentina: La Crujía.

Martini, S. (2000). Periodismo, noticia y noticiabilidad. Buenos Aires, Argentina: Norma.

Martini, S., y Pereyra, M. (Eds.). (2009). La irrupción del delito en la vida cotidiana. Buenos Aires, Argentina: Biblos.

McQuail, D. (1999). Introducción a la teoría de la comunicación de masas. Barcelona, España: Paidós Comunicación.

Ortega, P. (2010). Televisión Pública en América Latina. Los valores del mercado y las políticas del Estado. Infoamérica ICR, 21, 205-213.

Orza, G. F. (2002). Programación televisiva. Buenos Aires, Argentina: La Crujía.

Piscitelli, A. (2209). Nativos digitales. Dieta cognitiva, inteligencia colectiva y arquitecturas de la participación. Buenos Aires, Argentina: Santillana.

Rincón, 0. (Ed.). (2005). Televisión pública: del consumidor al ciudadano. Buenos Aires, Argentina: La Crujía.

Ruiz, A., y Albertini, E. (2008). Fuentes Periodísticas: concepto, clasificación y modos de uso. Tram(p)as de la Comunicación y la Cultura, 60, 14-25.

Sádaba, T. (2001). Origen, aplicación y límites de la "teoría del encuadre" (framing) en comunicación. Comunicación y sociedad, 14(2), 143-175.

Sádaba, T. (2007). Framing: el encuadre de las noticias. El binomio terrorismo-medios. Buenos Aires, Argentina: La Crujía.

Se mata a una mujer cada 18 horas. (4 de marzo de 2017). El Tiempo. Recuperado de https://www.tiempoar.com.ar/ nota/se-mata-a-una-mujer-cada-18-horas

Sistema de Información Cultural de la Argentina. (2017). Encuesta Nacional de Consumos Culturales 2017. Recuperado de https://www.sinca.gob.ar/VerDocumento.aspx?ldCategoria $=10$

Steimberg, 0. (1987). Prensa amarilla/prensa blanca: notas sobre una conocida y no definida oposición de géneros. En J. Rivera, y E. Romano, Claves del periodismo argentino actual (pp. 149-159). Buenos Aires, Argentina. Tarso.

Szeta, M., y Fulco, M. (2018). Nahir. La historia desconocida. Buenos Aires, Argentina: Sudamericana.

Unicef. (2017). Comunicación, Infancia y Adolescencia. Guía para periodistas. Perspectiva de género. Recuperado de https://www.unicef.org/argentina/sites/unicef.org.argentina/files/2018-04/COM-1_PerspectivaGenero_WEB.pdf

Valdettaro, S. (2010). Subjetividades y digitalización: bosquejo de un estado de la cuestión. En A. Fausto Neto y S. Valdettaro (Dirs.), Mediatización, sociedad y sentido: diálogos entre Argentina y Brasil (pp. 18-35). Recuperado de https://www.researchgate.net/publication/45588958_ Mediatizacion_sociedad_y_sentido_Dialogos_entre_Brasil_y_Argentina

Van Dijk, T. A. (1990). La noticia como discurso. Comprensión, estructura y producción de la información. Buenos Aires, Argentina: Paidós.

Van Dijk, T. A. (1997). Racismo y análisis crítico de los medios. Barcelona, España: Paidós.

Verón, E. (2009). El fin de la historia de un mueble. En M. Carlón, C. A. Scolari (Eds), El fin de los medios masivos. El comienzo de un debate (pp. 229-248). Buenos Aires, Argentina: La Crujía.

Contribución autoral

La concepción del trabajo científico, la recolección, interpretación y análisis de datos y la redacción/revisión del manuscrito fueron realizadas por Yamila Heram y María Paula Gago. Las dos autoras revisaron y aprobaron el contenido final. 